\title{
Estudo da Expressão de Genes relacionados com o Fuso Mitótico (AURKA e AURKB) e Ponto de Checagem Mitótico (CDC20 e MAD2L1) em Pacientes Portadores de Síndrome Mielodisplásica
} Study on Expression of Genes Related to Mitotic Spindle (AURKA and AURKB) and Mitotic Checkpoint (Cdc20 and MAD2L1) in Patients with Myelodysplastic Syndrome

Estudio de la Expresión de Genes Relacionados con el Huso Mitótico (AURKA y AURKB) y Puesto de Control Mitótico (CDC20 y MAD2L1) en Pacientes con Síndrome Mielodisplásica

\author{
Fabiola Fernandes Heredia ${ }^{1}$; Ronald Feitosa Pinheiro ${ }^{2}$
}

\section{Resumo}

Introdução: Estudos mostram que alterações na expressão de genes relacionados ao fuso mitótico ( $A U R K A$ e $A U R K B$ ) e ponto de checagem mitótico ( $C D C 20$ e MAD2L1) estão envolvidas na instabilidade cromossômica e progressão da doença em tumores sólidos e hematológicos. Objetivo: Avaliar o perfil de expressão desses genes em pacientes com síndrome mielodisplásica (SMD), e investigar sua relação com variáveis clínicas/laboratoriais da doença. Método: Amplificação dos genes AURKA e AURKB realizada por FISH e expressão de AURKA, AURKB, CDC20 e MAD2L1 realizada por qRT-PCR em 61 amostras de medula óssea (MO) de pacientes com SMD, oriundos do Hospital Universitário Walter Cantídio (CEP/HUWC No075.11.08). Amostras de MO de dez voluntários sadios constituiu o grupo controle. Resultados: Amplificação de $A U R K A$ foi observada em $10 \%$ dos casos, os quais também mostraram expressão mais elevada do que o controle $(\mathrm{p}=0,038)$. Pacientes com $\mathrm{MO}$ normo/hipercelular apresentaram maior expressão que pacientes com MO hipocelular ( $\mathrm{p}=0,0016 ; 0,0010 ; 0,0001 ;<0,0001$ para $A U R K A, A U R K B, C D C 20 \mathrm{e}$ $M A D 2 L 1$, respectivamente). Após regressão logística multinominal, os resultados mostraram associação entre níveis elevados de expressão dos genes estudados e risco aumentado de desenvolver SMD normo/hipercelular. Também indicaram que a idade (pacientes $\geq 60$ anos) está associada com níveis elevados de expressão de $A U R K A, C D C 20$ e MAD2L1. Conclusão: A expressão distinta dos pacientes hipocelulares enfatiza a importância prognóstica da celularidade na SMD e reforça a diferente patogênese dessa entidade. A amplificação e expressão elevada de AURKA sugerem que o aumento da expressão desse gene esteja relacionado com a patogênese da SMD.

Palavras-chave: Humanos; Síndromes Mielodisplásicas; Expressão Gênica; Amplificação de Genes

Suporte financeiro: CNPq e FUNCAP.

Tese apresentada para obtençáo do título de Doutor em Ciências no Programa de Pós-Graduação Interinstitucional em Oncologia, da Fundação Antônio Prudente em parceria com Escola Cearense de Oncologia.

${ }^{1}$ Bióloga. Doutora em Ciências pelo Programa de Pós-Graduação Interinstitucional em Oncologia da Fundação Antônio Prudente/Hospital A.C. Camargo em Parceria com Escola Cearense de Oncologia. Fortaleza (CE). Brasil. E-mail: fabiolafh@gmail.com.

${ }^{2}$ Médico. Doutor em Ciências Médicas e Biológicas. Universidade Federal de São Paulo (UNIFESP). Professor-Adjunto do Departamento de Ciências Médicas da Universidade Federal do Ceará (UFC). Fortaleza (CE). Brasil. E-mails: ronaldpinheiro@pq.cnpq.br / ronaldfpinheiro@uol.com.br.

Endereço para correspondência: Ronald Feitosa Pinheiro. Rua Pereira Valente, 738 - Meireles. Fortaleza (CE). Brasil. CEP: 60160-250. E-mail: ronaldpinheiro@pq.cnpq.br. 